\title{
Forty years on
}

\author{
R J LEMBERGER
}

It was 1000 am and John Smith, BMedSci (Open University), MB (Harvey School of Medicine), FRCS (UK), MD, PhD (Scunthorpe), was very bored. He had tried to spin out his morning list but had been unable to pretend that his first case, a dermoid, was anything but simple. Worth a frozen section though, you could never be too careful. He was taking a respite before the last remaining operation and had left his senior registrar to close the wound and registrar to apply the povidone dressing. As the decaffeinated coffee arrived through the wall hatch there was time for reflection. What would he do with himself when he retired next year? At 50 he might live another 60 years. He flipped a Mannitol spansule into the drink to ease his congested nose. It could not be any more dull than at present though. After all, there was very little left to operate on. As a student he had seen some of the very last cases of peptic ulceration, the addition of cimetidine to the water supply had seen to that. Nursery school bran had replaced cod liver oil, and this had made extinct most diseases of the large bowel. As a houseman he could just remember the theatre crowded with excited observers as a blustering Sir Heneage Hopkinson explored a diverticular abscess. "It's 10 years since I last saw one of these!" he extolled, gleefully splashing the pus about. "Pass the sucker please, nursey."

"The what, Sir?"

Of course medical research had a lot to answer for. $\mathrm{He}$ pontificated with some anguish and had to shift the weight off his chrome-cobalt ischial tuberosity acquired after a mishap on a Space Shuttle package holiday. Regrettably nearly all disease could be treated medically or simply prevented from even occurring. He mused over some scientific milestones. The latter day scourges of blackheads, baldness, piles, and halitosis had all met with their respective cures, severely diminishing waiting lists and general practitioners' surgeries. Interferon had seen off practically all infections, even the common cold. Gall stones could be dissolved in a few hours with a simple tablet. Cancer melted away with Rubean. This derivative of runner bean had been discovered by pure chance. A laboratory technician had been surreptitiously eating his lunch near a tumour tissue culture and, as his knife skidded across the plate on cutting his tough steak, a piece of runner bean fell in. He hid the bottle. Some days later the culture was found to be dead, and the terrified technician became famous. Atheroma was certainly caused by cigarettes but its severity did not fall when imitation tobacco was made compulsory. Of course it didn't, the causative agent was in the paper. Cigarettes were now made of shredded tobacco glued into columns and very nice they were too. There was so little trauma. Private transport had recently been abolished, and the safety record of the State system was $100 \%$. There was no street violence as there were simply no streets. Mental illness had vanished with the addition of endorphin to table salt. Fortunately, it was stable with iodine, magnesium, caffeine, and stilboestrol.

Irony furrowed his brow and dimpled his cheeks. Here he was being rueful about his present lot when he was partly responsible for vanquishing appendicitis. His friend Arnold had really cracked it though, one of the last great unknowns of medical science had yielded its secrets. For some years Arnold's exclusive task had been to delineate the cause of appendicitis and he had

Hallamshire Hospital, Sheffield S10 2JF

R J LEMBERGER, FRCS, surgical registrar found it. The application of an epsilon-squared Pupil's $S$ test had proved it conclusively. He relived the secretive childish titter he had enjoyed as he had enumerated the previous incriminations: tobacco inevitably, autoimmune inflammation, aspirin, and salami rind. Nor was it lack of bran. Of course, Africans emigrating to the United States increased their incidence of appendicitis but it wasn't the fibre. Oh no, it was the talcum powder. And that was why it was commoner in children: mothers smothering their kiddies in the stuff. To think, from then on every container had to carry a government health warning. With sadness he recalled bidding Arnold farewell. No longer needed, Arnold, a computer, was switched off, closing down his memory banks forever.

The profession had really lost its grip on medical research. It had all become so logical, so meticulous, so unstoppable that an answer was inevitable. Luck had been completely abolished. In the 1990s house jobs had included 9 years' research necessary for full registration. You couldn't get an SHO job without an MD. Everyone was doing research. There were so many journals they were no longer printed and appeared as microdots on the postage stamps that delivered them. Trials had become so complex that they were christened triple-blind as even the investigators were uncertain of the obtained results. But the computers did most of the work anyway, applying a new drug to a programmed pathophysiological disease and calculating the result. The irritating inconsistencies of the academic's mind and the patient's disease had thereby been obviated. Experimental animals were so sophisticated too. The Wistarmatic rat had a natty little abdominal zipper to allow repeated surgery. Pig husbandry had yielded creatures with metabolism closer to a human being's than a medical student's, which was quite a relief really as it allowed students to concentrate on their PhDs.

But it had all slowed down. There was so little left to be discovered. The British Medical fournal often appeared with no original papers at all, and people took it merely for the job advertisements. How things had changed! The Pansy Report, reorganising the Nether Wallop medical schools, had farreaching effects and many professorial units were disbanded, returning doctors to the wards. Not that there was much for them to do there. It was all computer screening and pills. In fact some practitioners had been accused of deliberately holding back discoveries to safeguard their jobs. Smith tut-tutted but with a distinct lack of moral condemnation.

He himself had been unemployed for a brief period, just the four years soon after he had obtained his PhD. He was somewhat aggrieved as he had written 98 papers and what was to become a standard work. This book, Life with an Ingrowing Toe Nail, had received very favourable reviews in the Welsh fournal of Paronychia and had gone on to become a bestseller. It had all been very humiliating; he hadn't even been able to get a lecturer's post at the Hammersmith. Giving up medicine altogether had crossed his mind, but as he was then doing orthopaedics many prospective employers did not consider him bright enough to do anything else. Eventually his luck changed and he landed a prized job as an SHO in geriatrics. It was with some sadness that he eventually left the dole queue for the splendour of a small 8000 -bedded hospital. The redundancy pay had purchased a small Ferrari, which was readily run on his social security benefit. Now this would have to go. You couldn't afford these luxuries when you were holding down a job. But he really had been lucky, for geriatrics was the foremost specialty of 
the day. After all, $86^{\circ}{ }^{\circ}$ of the population were over 75 . The facilities were marvellous. There were lavatories that rose to meet their arthritic user's buttocks, vast gymnasia to gird up those tired limbs into a state of balletic suppleness, and hairdressing gadgetry that could transform the much-loved bluerinse perm into almost anything. The wards were busy with the hum of motorised Zimmer frames weaving their owners in between the climbing frames and dumb-bells. How he had loved the prestige of it all but, alas, the competition had been too intense. He just could not get on and reluctantly took his chief's advice and dropped out into surgery. What ignominy! All those times as a geriatrician when he had had to wait weeks for a surgeon to see a patient let alone take over his care. And all those old, decrepit buildings starved of money. But there were compensations. In this unpopular backwater promotion was certainly rapid: consultancy in 20 years.

In fact he quite enjoyed operating, until the unions made it almost impossible. You could do nothing without consulting the local chapel of the Junior Hospital Doctors Association. It all came to a head in theatre one day when he asked his house person, a rather opinionated Burnley graduate by the name of Scargill, to cut the suture.

"Cut please ... Well, cut it."

"Sorry Sir, I can't."

"Why not?"

"Well at this present moment in time we are in point of fact in dispute with the management over the introduction of sutureless skin closure materials, which are a threat to our job security."

Smith had bitten hard on his lip under the camouflage of his mask while he silently enumerated other possible threats to Scargill's job. "Give the scissors here. I'll cut it."

"I am afraid, Sir, if you do that, I will have to call my brothers out forthwith."

"Well what do I do then ?" Smith hissed between his clenched teeth.

"Brother Scanlon is cutting sutures this week, and he will be available on completion of the cystoscopy in theatre 2."

"But you don't need stitches for cystoscopies."

"Er no. Not always."

Eventually Smith had solved it by having only two inches of suture on each needle so there were no ends to cut. Honour was ultimately satisfied for everyone as the end-cutters became the mopper-uppers of any excess glue.

A brief moment of alarm overtook him. Had he clocked in that morning ? Yes, yes he had. He remembered the deputy assistant sector administrator glowering at him as he arrived confidently early again. Pay wasn't so good these days. The emergency recall scheme retained by the Government to augment the salary was a farce. There just weren't any emergencies. Still, they did have some excitement last week when a suspected wound infection eventually turned out to be some stray mayonnaise. But it did shut the hospital for two days. Such was the stringency of sepsis precautions. These days one had to be very careful in all things. This litigation had got quite out of hand. A solicitor was present when the consent form was signed and the spy-in-the-theatre cameras recorded everything. You could not make any jokes lest they came out in court later. Anyway, patients often underwent surgery with local anaesthetic alone so that they could see and direct the surgeon. They were for ever asking for the light to be adjusted, the diathermy to be upped, the swabs to be changed, the glue to be applied more liberally. He remembered how in frustration one day he had thrown down the instruments and bellowed at the patient, "Why don't you do it yourself then ?"

"I can't. I'm not qualified."

Now as he neared his dotage, had the struggle he'd endured been worthwhile? He had finally been appointed five years ago. The accreditation in surgery required 12 years of senior registrar grade spending six months in each specialty. He had plumped for dermal surgery: cystic lesions, which still provided a good deal of cutting. His waiting list was usually well over two weeks. There was some satisfaction here as he enjoyed working hard. But with the job creation schemes the junior ranks had proliferated, and he could hardly find the work for his three housemen, four senior house officers, four registrars, two research fellows, and two senior registrars.

What had he actually achieved? There was a long pause in his mentation as he chewed on his thumb, his crossed leg swinging in precise arcs on its new femoral gimbals. He was bored and it would get worse. He had worked hard and done all that was asked of him. There'd been the nights with no sleep, the days with no time for meals, the soul-destroying years of frustration with research, the demeaning wait for a job. He abhorred the infinite hindrances invented by the administrative bureaucracy. All that and he'd ended up doing something he did not want to do in a place he did not want to do it in. In this moment of realisation, an awful silence enveloped the grieving surgeon.

"Mr Smith, we are ready."

Stagnant coffee disappeared in a few gulps as he snapped back to the task in hand. "Thank Heavens they haven't found a medical cure for sebaceous cysts," he enthused. He plunged his hands under the gamma steriliser for the customary two seconds and strode into the theatre. "Hello Mrs Brown, this won't take long." The patient was reassured by his calm confidence. The anaesthetist probed his acupuncture needles into place.

"OK John, it should be numb now."

"Thanks Bob. Laser, please, nurse."

(Accepted 5 August 1981)
ONE HUNDRED YEARS AGO George Eliot. The circumstances of the sudden illness which has so prematurely and rapidly cut short the mortal career of this gifted writer are, we understand, briefly these. On the Saturday preceding her death, Mrs Cross attended an afternoon concert, and appeared to her husband to be sitting in a draught. She did not, however, feel the effects of it at the time; and did not complain of cold, or feel the necessity of sheltering herself from it. On Sunday, Mrs Cross appeared well, and received several of her friends; amongst these, Mr Herbert Spencer. On Monday, she complained of feeling unwell, and was seen by a local medical man, Mr G W Mackenzie, who found her suffering from some slight laryngeal catarrh. On Wednesday, Mr Mackenzie found her markedly changed for the worse, with rapid breathing and hurried pulse, and very prostrate. In the evening, at six o'clock, when he met Dr Andrew Clark, who had been sent for in consultation, her state was critical in the extreme. There was marked dyspnoea, rapid pericardial pulse; and, on examination of the heart, he found that vital organ labouring heavily through an unusually large quantity of diffused lymph. It was quite clear that she was moribund. There was a cold grey look about her face; her eyes were fixed; and she was almost unconscious. In a few hours after Dr Andrew Clark's visit, she expired. This would appear to be a sudden death, were it not that these symptoms were the outcome of a long-standing disease. Seven years ago, she was first seen by Dr Clark, and was complaining of severe lumbar pain; and there were other indications of renal disease, which were relieved by treatment. Dr Clark then inferred that, in all probability, a renal calculus was forming. A year later, he again saw her with Dr Parsons, when she had an acute attack of pyelitis. During succeeding years, she suffered from further attacks of the like character. There is no doubt that chronic renal induration supervened. The results of these continued attacks, and of the chronic renal change, were to lower the resisting vital powers of the sufferer; and so, when at last a slight storm came, she had no longer powers left to enable her to successfully contend with it. (British Medical fournal, 1881.) 